\title{
Aneurysmal rib cyst
}

\author{
Sotirios Moraitis', Dimitrios Moraitis², Maria Chounti², Panagiotis Hountis1 \\ 1 Department of Thoracic and Cardiovascular Surgery, Athens Naval and Veterans Hospital, Athens \\ 2 Department of Administration and Statistics, Athens Naval and Veterans Hospital, Athens \\ 3 Nursing School-Technological Institute of Patra, Greece
}

\begin{abstract}
Thoracic cage is the site of development of various primary or metastatic tumors. An aneurysmal rib cyst is a benign tumor arising from the chest wall. Aneurysmal rib cyst is considered a rare surgical entity and its presence must be followed by removal for histology examination. We present here the case of an aneurysmal rib cyst to a young 33-year-old female. The tumor was presented as an expanding left anterior second rib mass during a self-breast examination. Chest x-ray showed a shadow on the left upper lung area and CT scan revealed a large multicystic mass in the anterolateral left $2^{\text {nd }}$ rib protruding underneath the thoracic major muscle. We discuss the clinicopathological characteristics of this tumor and its surgical management along with a short literature review.
\end{abstract}

\section{Introduction}

Primary rib neoplasms comprise 5-7\% of all primary bone tumors [1]. Aneurysmal Bone Cyst ( $\mathrm{ABC}$ ) is an unusual benign mass that has the potential for rapid growth, bone destruction, and extension into adjacent soft tissue with a thin wall, containing blood-filled cystic cavities. In this study, we discuss the case of a 33-year-old female who was presented with an expandable mass on her left anterior chest wall, raising the major thoracic muscle. Initial clinical examination was highly suspicious for breast cancer. The second rib along with the $\mathrm{ABC}$ was surgically removed.

Corresponding author: Panagiotis Hountis, Department of Thoracic and Cardiovascular Surgery, Athens Naval and Veterans Hospital, Deinokratous 70, 11521 Athens, Greece.

Tel. +30.6986004089. E-mail: panos_hountis@hotmail.com

Key words: Aneurysmal rib cyst; rib; tumor.

Conflict of interest: the authors declare no conflict of interest.

Received for publication: 26 May 2017

Accepted for publication: 26 August 2017

(C) Copyright S. Moraitis et al., 2017

Tipografia PI-ME Editrice, Italy

Monaldi Archives for Chest Disease 2017; 87:860

doi: 10.4081/monaldi.2017.860

This article is distributed under the terms of the Creative Commons Attribution Noncommercial License (by-nc 4.0) which permits any noncommercial use, distribution, and reproduction in any medium, provided the original author(s) and source are credited.

\section{Case report}

A 33-year-old female was admitted to the Cardiothoracic Department of the Athens Naval and Veterans Hospital due to a left anterior thoracic wall mass. She discovered a mass in her left breast during a regular monthly self- breast examination and she was subjected to mammography and ultrasound that disclosed the absence of pathology from the breast and the presence of a mass on the anterior thoracic wall. She had no history of trauma, fever, pain or respiratory disease accompanying the mass. On physical examination, the left anterior chest wall protruded underneath the left breast but it was not tender to palpation. Plain and lateral chest radiographs revealed an anterior chest mass on the left side. Computed tomography (CT) of the chest revealed an irregular-shaped $7 \times 6 \times 5 \mathrm{~cm}$ tumor anteriorly in the area of the $2^{\text {nd }}$ rib. In the core of the tumor there was a prominent calcification. The mass expanded and destroyed a part of the $2^{\text {nd }}$ rib (Figures 1 and 2). A radionuclide bone scan showed increased uptake at the site of the lesion and no other abnormalities. A decision was taken not to perform a biopsy prior to the final operation due to the high possibility of dealing with a malignancy and spread of neoplasmatic cells in the adjacent tissues. A left sided anterolateral thoracotomy was performed with complete en bloc removal of the $2^{\text {nd }}$ rib along with clear surgical margins with subsequent removal of periosteum and intercostal muscles (Figure 3). Microscopic examination demonstrated multiple blood-filled cavernous spaces that were separated by fibrous connective tissue, osteoclastic giant cells and vascular spaces with hemorrhages in the septa lining the cystic spaces. There were focal areas of calcification and osteoid. The surgical margin was free. The microscopic examination was diagnostic of ABC. The chest wall was reconstructed with a double layered Prolene mesh. She was discharged the $5^{\text {th }}$ post-operative day in excellent clinical condition. The patient has been followed for the last 3 years and is asymptomatic with no evidence of recurrence.

\section{Discussion}

Primary rib neoplasms comprise $5-7 \%$ of all primary bone tumors [2]. Aneurysmal Bone Cyst (ABC) is an unusual benign mass that has the potential for rapid growth, bone destruction, and extension into adjacent soft tissue with a thin wall, containing blood-filled cystic cavities. Jaffe and Lichtenstein [3,4] first reported the clinical presentation, pathology, and radiographic appearance of Aneurysmal Bone Cyst (ABC) in 1942. It is usually presenting as a rapidly expandable protrusion and local symptoms indistinguishable compared to that of a malignant bone tumor. Its pathology is characterized by cavernous channels surrounded by a spindle cell stroma with osteoclast-like giant cells and osteoid production [5]. It is supposed that tumor development arises de novo in bones. In $30 \%$ of 


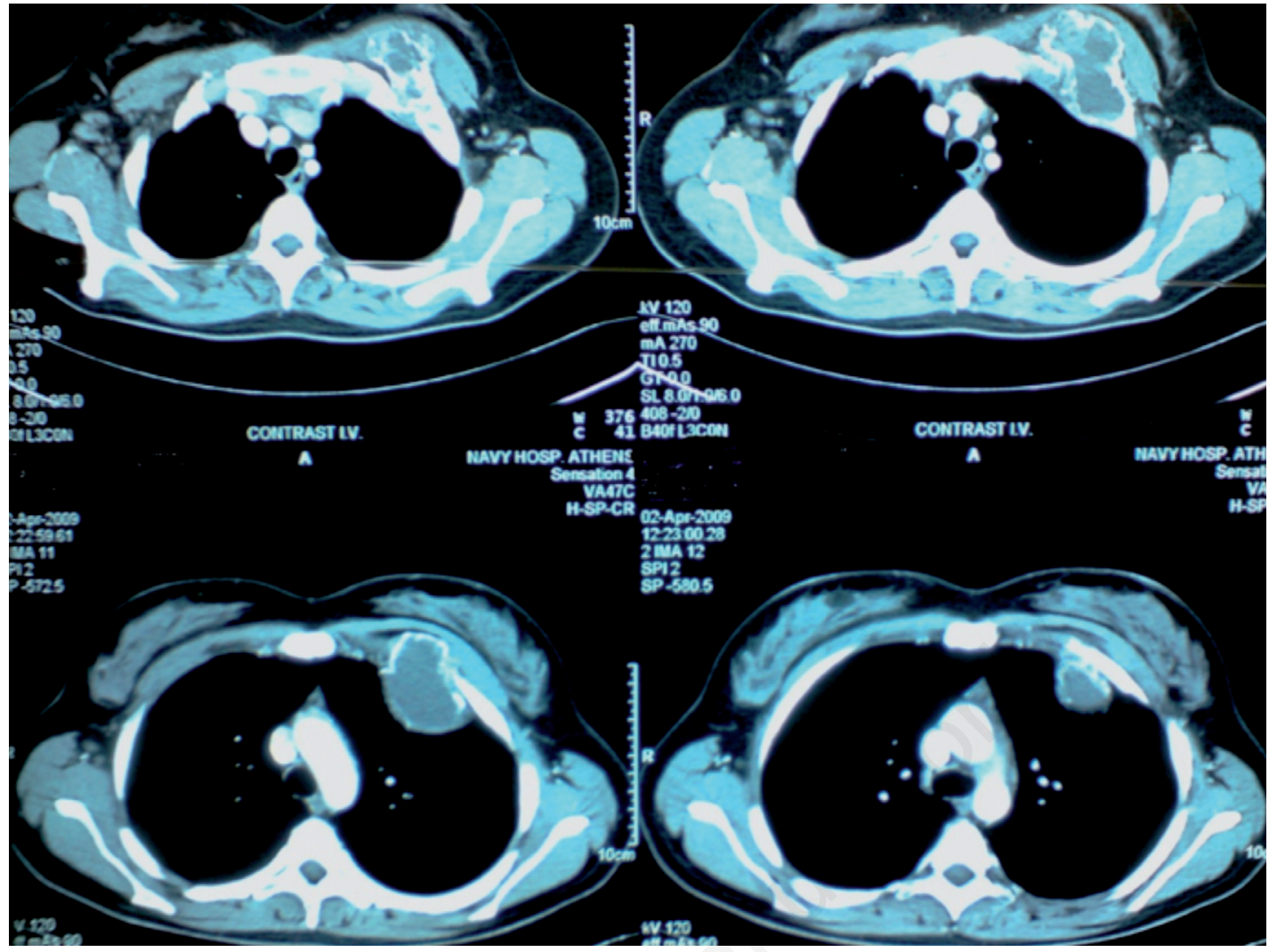

Figure 1. Chest CT scan showing the presence of the tumor in a high position arising from the $2^{\text {nd }}$ left rib.

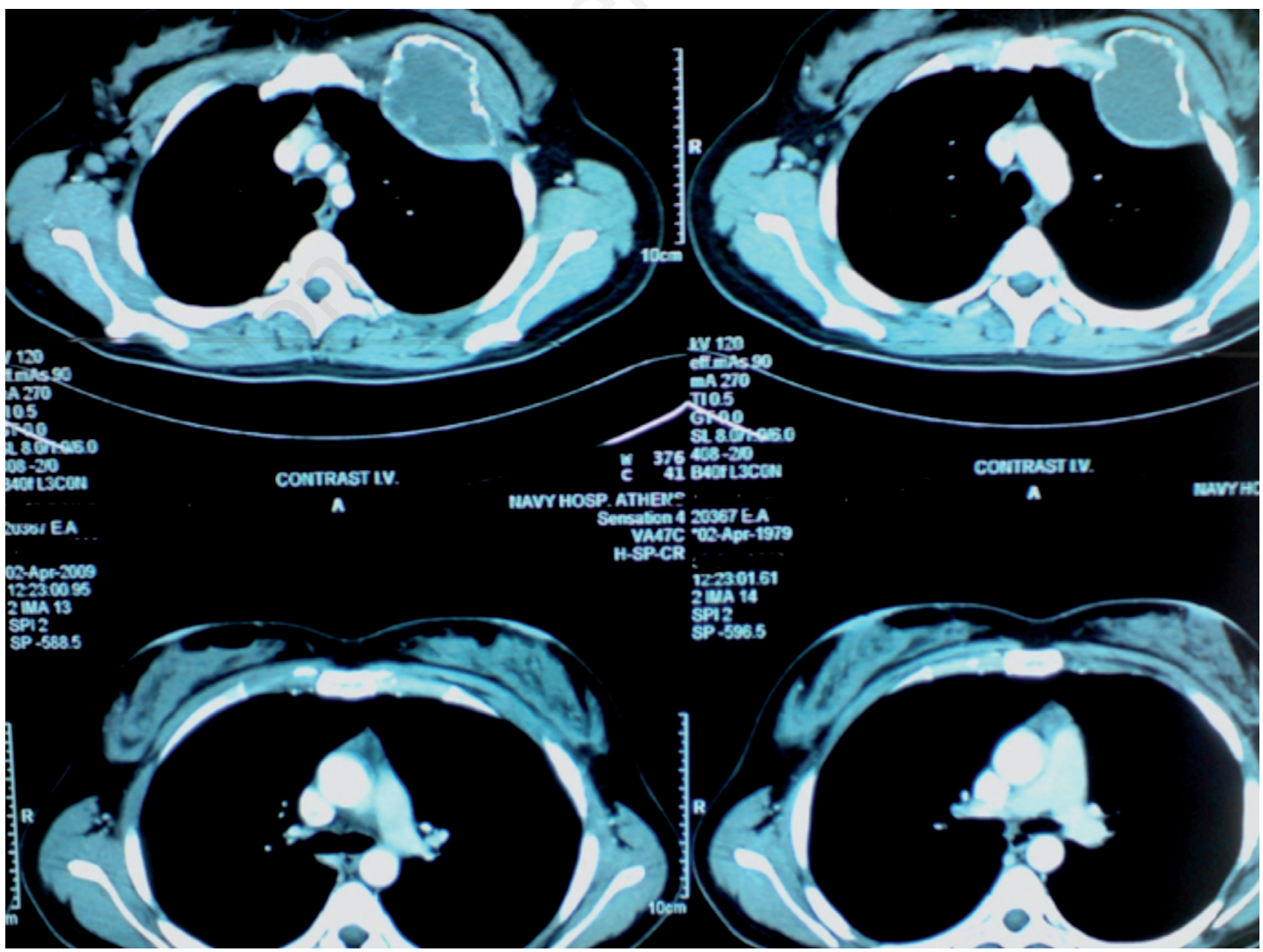

Figure 2. Chest CT scan. The tumor protrudes and raises the left thoracic major muscle. 
cases pre-existing bone lesions have been identified histologically [6]. The second rib is extremely rare location for $\mathrm{ABC}$. The term aneurysmal is derived from its radiographic appearance. It may mimic a sarcoma in the ribs, scapula, or sternum, especially when associated with a large soft-tissue component [7]. It comprises $1.3 \%$ of all primary bone tumors [8]. This tumor predominantly affects children, with $60 \%$ of patients being younger than 20 years old; the peak incidence is during the second decade of life, and there is a slight preponderance for women over men [3].

Bertoni et al. [9] in a review of 15 cases of the solid variant of aneurysmal bone cyst, reported the patient age distribution between 2-49 (mean 23 years) and the male: female ratio 1:1.5. The femur and tibia were the most commonly affected sites. Ribs were seldom affected.

In the literature, the development of the tumor is considered to be a result of high venous pressure or trauma. These have the potential of causing bone absorption and blood-filled cyst formation explaining the expansible nature of $\mathrm{ABC}$ [4]. The masses contain a network of multiple blood-filled cysts lined by fibroblasts and multinucleated giant cells of the osteoclast type. Secondary lesions commonly associated with $\mathrm{ABC}$ are giant cell tumor of bone, chondroblastoma, chondromyxoid fibroma, and fibrous dysplasia. Hemodynamic changes that take place in these lesions have been shown to contribute to the formation of arteriovenous fistulae. The raised intraosseous-vascular pressure will eventually cause bone expansion [10]. Other bone diseases have been theoretically considered as pre-existing conditions that may cause the secondary form of $\mathrm{ABC}$ [11].

Symptoms that have been associated with $\mathrm{ABC}$ are chest pain, swelling of the chest wall, dyspnea, paraplegia and pathological fractures. Some patients are completely asymptomatic. Incidental diagnosis may be done when an x-ray has been performed for irrelevant reason e.g. pre- employment, respiratory infections. In this case the initial finding of the patient was a mass that was incidentally found on a regular monthly basis self- breast examination of the patient. This finding prompted for a diagnostic process that eventually diagnosed the aneurysmal second rib cyst.

Computerized tomography shows a destructive pattern of rib lesions with a 'soap bubble' or 'honeycomb' appearance [12]. Differential diagnosis of $\mathrm{ABC}$ includes benign and malignant bone tumors such as Ewing sarcoma, eosinophilic granuloma, solitary bone cyst, hemangioma, osteosarcoma, giant cell tumor, and chondroblastoma.

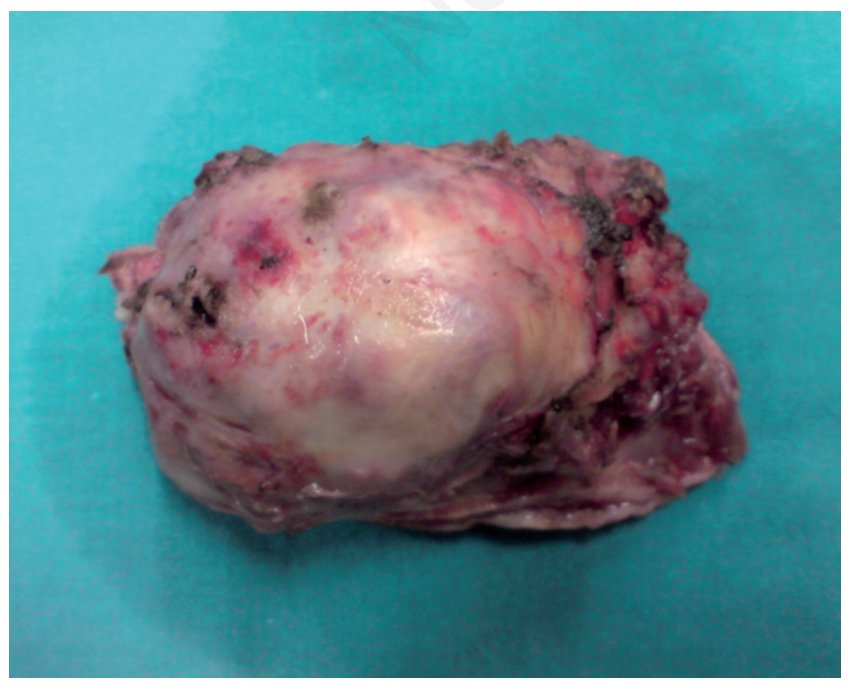

Figure 3. The tumor that has been surgically removed.
When an $\mathrm{ABC}$ is diagnosed or suspected, treatment should be planned as soon as possible since local extension and rapid growth can cause pathologic fractures, paralysis due to spinal cord compression, compression of the vital organs and malignant transformation. Core needle biopsy specimens may increase the risk of bleeding due to the abundant blood cysts inside the $\mathrm{ABC}$ and must be used cautiously if desired [13].

Any other treatment option (selective arterial embolization, sclerotherapy, radiotherapy) is considered as incomplete with high risk of recurrence or as dangerous due to the high risk of bleeding. Radiotherapy should be considered only for inoperable cases. Extreme care should be taken with regard to the use of irradiation, as there is the possibility of a late development of sarcoma [14].

\section{Conclusions}

Aneurysmal rib cyst is a rare benign entity, which should be considered in the differential diagnosis of chest wall tumors. Due to the same clinical and radiographic appearance of the disease with bone malignant tumors we feel that complete surgical excision offers the best chance of cure. Diagnostic process may be extremely dangerous due to the presence of blood filled cavities and must be judiciously planned.

\section{References}

1. Cappana R, Albisinni U, Picci P, et al. Aneurysmal bone cyst of the spine. J Bone Joint Surg Am 1985;67:527-31.

2. Guo J, Liang C. A giant aneurysmal bone cyst of the rib: Case report. Oncol Lett 2014;7:267-9.

3. Jaffe HL, Lichtenstein L. Solitary unicameral bone cyst with emphasis on the roentgen picture, the pathologic appearance and the pathogenesis. Arch Surg 1942;44:1004-25.

4. Al-Shamy G, Relyea K, Adesina A, et al. Solid variant of aneurysmal bone cyst of the thoracic spine: a case report. J Med Case Rep 2011; $30 ; 5: 261$.

5. Martinez V, Sissons HA. Aneurysmal bone cyst. A review of 123 cases including primary lesions and those secondary to other bone pathology. Cancer 1988;61:2291-304.

6. Güneş D, Mutafoğlu-Uysal K, Sarialioğlu F, et al. Aneurysmal bone cyst of rib presenting as a huge chest wall mass. Turk J Pediatr 2009;51:82-5.

7. Yasaroglu M, Ketenci B, Demirbag H, et al. Aneurysmal bone cyst of the rib: a case report. J Med Case Rep 2009;9;3:8457.

8. Bertoni F, Bacchinin P, Capanna R, et al. Solid variant of aneurysmal bone cyst. Cancer 1993;71:729-34.

9. Mahadevappa A, Patel S, Ravishankar S, Manjunath GV. Monostotic fibrous dysplasia of the rib: a case report. Case Rep Orthop 2012;2012:690914.

10. Kransdorf MJ, Sweet DE. Aneurysmal bone cyst: concept, controversy, clinical presentation, and imaging. AJR Am J Roentgenol 1995;164:573-80.

11. Soyer T, Karnak I, Talim B, Tanyel FC. Aneurysmal bone cyst of the rib in a child: report of a case. Surg Today 2005;35:886-9.

12. Cheng C, Yeung SC, Zhong FT, et al. Aneurysmal bone cyst in the first rib. Ann Thorac Surg 2008;85:2118-20.

13. Tillman BP, Dahlin DC, Lipscomb PR, Stewart JR. Aneurysmal bone cyst: an analysis of ninety-five cases. Mayo Clin Proc 1968; 43:478-95. 